\title{
Fatores que Influenciam a Prática do Consumo Colaborativo: uma revisão sistemática
}

Factors that Influence the Practice of Collaborative Consumption: a systematic review

Maria Eduarda Pedrosa Sales ${ }^{1}$, Ângela Cristina Rocha de Souza ${ }^{1 *}$, Maria Iraê de Souza Corrêa ${ }^{1}$, Ionete Cavalcanti de Moraes ${ }^{1}$

${ }^{1}$ Universidade Federal Rural de Pernambuco, Pernambuco, Brasil.

\begin{tabular}{|c|c|}
\hline I NFO A R T I GO & R E S U MO \\
\hline $\begin{array}{l}\text { Palavras-chave: } \\
\text { Economia compartilhada, } \\
\text { Consumo colaborativo, } \\
\text { Motivos, } \\
\text { Benefícios, } \\
\text { Riscos. }\end{array}$ & $\begin{array}{l}\text { O objetivo da pesquisa foi realizar uma revisão sistemática da literatura } \\
\text { acadêmica brasileira sobre fatores que influenciam o consumidor a praticar o } \\
\text { consumo colaborativo. Os resultados mostram que a principal motivação para } \\
\text { a prática do consumo colaborativo é o fator ambiental, que contribui para o } \\
\text { consumo consciente e evita o desperdício de recursos. Já em relação aos } \\
\text { riscos, podemos evidenciar que a falta de confiança em relação ao } \\
\text { compartilhamento com desconhecidos e o risco de perda de recursos } \\
\text { monetários foram os mais mencionados pelos autores. Por fim, identificamos } \\
\text { que o principal benefício associado pelos consumidores ao consumo } \\
\text { colaborativo é o econômico, que engloba: ajuda financeira, economia de } \\
\text { dinheiro e diminuição de custos. Concluímos que os motivos, benefícios e } \\
\text { riscos identificados nesta revisão sistemática da literatura acadêmica } \\
\text { brasileira correspondem àqueles apontados na literatura sobre consumo } \\
\text { colaborativo. }\end{array}$ \\
\hline A R T ICLE I NFO & A B S T R A C T \\
\hline $\begin{array}{l}\text { Keywords: } \\
\text { Shared economy, } \\
\text { Collaborative } \\
\text { consumption, } \\
\text { Reasons, } \\
\text { Benefits, } \\
\text { Risks. }\end{array}$ & $\begin{array}{l}\text { The objective of the research was to conduct a systematic review of the } \\
\text { Brazilian academic literature on factors that influence consumers to practice } \\
\text { collaborative consumption. The results show that the main motivation for the } \\
\text { practice of collaborative consumption is the environmental factor, which } \\
\text { contributes to conscious consumption and avoids the waste of resources. } \\
\text { Regarding risks, we can evidence that the lack of confidence in sharing with } \\
\text { strangers and the risk of loss of monetary resources were the most mentioned } \\
\text { by the authors. Finally, we identified that the main benefit associated by } \\
\text { consumers with collaborative consumption is economic, which includes: } \\
\text { financial aid, money savings and cost reduction. We conclude that the reasons, } \\
\text { benefits and risks identified in this systematic review of the Brazilian } \\
\text { academic literature correspond to those pointed out in the literature on } \\
\text { collaborative consumption. }\end{array}$ \\
\hline
\end{tabular}

\section{Introdução}

No século XX, os modelos de consumo eram marcados predominantemente pela aquisição e concentração de bens. Já com a chegada do século XXI, emergem novas formas de consumo e outro tipo de consumidor: aquele que em vez de fazer uma compra, desfruta de um serviço ou experiência que um produto disponibiliza. Esse consumidor está mais responsável quando se trata das suas práticas de compra, se preocupando com o bem-estar

\footnotetext{
* Correspondência para autor: eduarda.saless10@gmail.com (Sales, M.E.P.) (ORCID: 0000-0002-3528-781X), acsouza@gmail.com (de Souza, A.C.R.) (ORCID: 0000-0001-6349-5168), mariairae.correa@ufrpe.br (Corrêa, M.I.S.) (ORCID: 0000-0002-8958-6583), ionete.moraes@ufrpe.br (de Moraes, I.C.).
}

1679-1827 C 2019 Gest@o.org. 
social antes mesmo do seu desejo pessoal (BARBIERI, 2015). Fajardo (2010, p. 23) explana esse novo perfil de consumidor: "ao comprar, ele procura apoiar relações produtivas e comerciais coerentes com seus valores, que são o respeito pelo ser humano, o equilíbrio e a valorização da vida".

Assim, esse novo consumidor vai ao encontro dos novos modelos de negócios que estão emergindo e que promovem a ideia de colaboração e de compartilhamento do consumo. Para Belk (2013), o compartilhamento faz um grande sentido prático e econômico para o consumidor, o meio ambiente e a comunidade. Também faz-se necessário o bom senso para os negócios que são suficientemente flexíveis, inovadores e com visão de futuro. Já o consumo colaborativo pode ser compreendido como um conjunto de práticas alternativas de consumo com diversos tipos de finalidade, que direcionam para uma mesma origem em comum: o ato de compartilhar (BOTSMAN; ROGERS, 2011).

$\mathrm{O}$ ato de colaboração no tocante ao consumo colaborativo pode ser associado a práticas locais realizadas pessoalmente entre indivíduos, como também ao uso de websites para interligar, formar grupos e localizar algo ou alguém, buscando gerar uma relação entre pares. De forma simplificada, os indivíduos estão buscando compartir produtos e serviços, ou seja, compartilhando escritórios, condomínio de apartamentos ou uma página nas redes sociais, entre outros. Belk (1988) afirma que a sociedade está vivendo um momento em que a antiga máxima: "você é o que você possui" se transforma em uma nova máxima: "você é o que você compartilha", e evidencia que as pessoas estão entrando em uma economia pós-propriedade (FARAH, 2019).

Nesse contexto, a economia compartilhada e o consumo colaborativo vêm crescendo em todo o Brasil. Embora ainda estejamos carentes de números referentes a sua evolução no país, segundo a agência Globo (2017, s.p.), "estimativas de especialistas indicam que a economia compartilhada tem potencial para contribuir, a médio e longo prazos, com mais de 30\% do Produto Interno Bruto (PIB) do setor de serviços no Brasil". Coutinho (2015) também afirma haver uma crescente no Brasil no âmbito do consumo colaborativo.

Embora em crescimento, um problema que se coloca diz respeito ao que leva os consumidores a adotar práticas de consumo colaborativo. Considerando os diferentes tipos de negócios relacionados a essa prática, ponderamos, por exemplo, se a questão da sustentabilidade ambiental é um motivador que permeia todas as formas de consumo colaborativo, como afirma Botsman e Rogers (2011). Assim, questionamos: que fatores influenciam o consumidor a praticar o consumo colaborativo? Mais especificamente, quais os motivos, benefícios e riscos o consumidor associa a essa forma de consumo?

Para responder aos questionamentos apresentados, optamos por buscar as informações em estudos desenvolvidos na academia brasileira. Assim, o objetivo geral da pesquisa foi realizar uma revisão sistemática da literatura acadêmica nacional sobre fatores que influenciam o consumidor a praticar o consumo colaborativo. Como objetivos específicos temos: selecionar artigos acadêmicos sobre fatores que influenciam os consumidores a praticar o consumo colaborativo; identificar os motivos que levam os consumidores a adotar práticas de consumo colaborativo; identificar os riscos e os benefícios associados pelos consumidores ao consumo colaborativo.

Desta forma, os resultados da pesquisa podem contribuir com conhecimentos relacionados ao comportamento do consumidor de negócios colaborativos, ao mesmo tempo que uma compreensão dos fatores que influenciam a prática do consumo colaborativo também poderá trazer subsídios para os gestores e empreendedores desses negócios. Por outro lado, a revisão sistemática também pode identificar lacunas nos estudos sobre o tema.

\section{Referencial Teórico}

\subsection{Consumo colaborativo}

A visão da natureza humana, segundo Olson (1965), é que o homem é maximizador de riquezas, individualista, avesso ao risco, detentor de plena informação e que só opera coletivamente por meio de coerção, quando há objetivos de grupo. Entretanto, de maneira contraditória, atitudes colaborativas foram surgindo a partir dos próprios indivíduos e despertaram interesses de pesquisadores.

Ostrom (2000), em contrapartida à reflexão de Olson (1965), afirmou que a conduta e as práticas coletivas são a base para o consumo colaborativo e a confiabilidade recíproca é um simplificador para tais ações, dando origem à Teoria da Colaboração. Nessa perspectiva, a teoria de Ostrom aponta que é provável a existência de um sistema colaborativo eficiente, desde que os conceitos e regras da propriedade coletiva estejam bem estabelecidos, sejam aprovados e respeitados por todos.

O consumo colaborativo, inicialmente apresentado por Algar (2007) e abordado posteriormente por Botsman e Rogers (2011), é um novo modelo de consumo que recupera práticas antigas de empréstimos comerciais, aluguéis e trocas que eram muito tradicionais, porém entraram em desuso desde a emergência do modelo capitalista de 
produção (ALGAR, 2007).

Esta forma de consumo, no entanto, vem ganhando participação expressiva no mercado nos últimos anos, conquistando esse prestígio por desenvolver uma forma atrativa de consumo, incluindo o colaborador em todo o processo de aquisição, de forma que ele consiga produzir resultados. Para Botsman e Rogers (2011), o consumo colaborativo é uma forma atraente e sustentável de realizar desejos e suprir necessidades, representando um ônus muito baixo para o interessado. Ele se fundamenta na ideia de que pessoas compartilham recursos sem abrir mão da autonomia pessoal e sem abandonar seu estilo de vida.

Como afirma Belk (2010), o consumo colaborativo se fundamenta especialmente na lógica de compartilhamento de bens e serviços entre os indivíduos. Esta ação social se difundiu, nos últimos anos, devido ao partilhamento de bens individuais que estavam em desuso. A partir desse compartilhamento, por meio de negociações consumer-to-consumer (C2C) e business-to-consumer (B2C) (CHOI et al., 2014), possibilita-se um aproveitamento mais responsável do excesso de bens e/ou produtos através do uso progressivo das redes sociais, do engajamento entre as pessoas e do oferecimento da proteção e da segurança entre esses pares (MENDES; CEROY, 2015).

As plataformas de compartilhamento dispõem de uma proximidade entre os consumidores, o que de acordo com Belk (2014), não só impede o exagero do consumo e das posses de produtos que se tornam improdutivos, bem como, possibilita um senso de comunidade. Esse senso de coletividade, poderá ampliar os níveis de bemestar, especialmente o bem-estar social. Em consonância, Botsman e Rogers (2011) relatam que, nas atividades de empréstimos, compartilhamento, escambo, trocas, locação e outras, verifica-se que a colaboração é a solução dos comportamentos sociais, visto que, o ato de colaborar traz benefícios para ambas as partes do processo; além disso, faz com que os cidadãos se tornem mais participativos na sociedade.

O consumidor, ao assumir o comportamento de consumo colaborativo, tem como propósito a utilização do produto e a prestação de serviço, ou seja, a possibilidade de acesso aos bens e à experiência pelo período necessário de uso em vez de manter a posse definitiva do objeto (BARDHI; ECKHARDT, 2012). Um dos benefícios da prática do consumo colaborativo está em proporcionar um consumo mais sustentável e com menor ônus ao consumidor (BOTSMAN; ROGERS, 2011).

Botsman e Rogers (2011) evidenciam outros fatores essenciais para o êxito das iniciativas de consumo colaborativo, que são a certeza no bem comum e confiabilidade entre estranhos, e descrevem o consumo colaborativo como um fenômeno socioeconômico que transforma o modo como as organizações pensam sobre suas propostas de valor e modifica também a forma como as pessoas satisfazem suas necessidades. Com o consumo colaborativo busca-se uma harmonia entre as necessidades individuais, da sociedade e do planeta. Os indivíduos prosseguirão adquirindo bens, e as organizações vendendo e atendendo as demandas, o que modifica é a maneira como isso irá acontecer.

Outro aspecto relevante para o sucesso do consumo colaborativo é o desenvolvimento de novas tecnologias de informação e comunicação. O consumo colaborativo não só emergiu, mas teve acelerada sua expansão nos modos convencionais de compartilhamento, troca, empréstimo e locação a partir da tecnologia de rede em grande escala (ORNELLAS, 2012; BOTSMAN; ROGERS, 2011; ALGAR, 2007). Botsman e Rogers (2011, p. 18) ressaltam que "o consumo colaborativo inicialmente se manifestou on-line, com a publicação de comentários e o compartilhamento de arquivos, códigos, fotos, vídeos e conhecimento".

$\mathrm{O}$ ato do consumo colaborativo esbarra em dificuldades de confiança e no impasse em saber quem tem o que ou quem pode estar precisando de algo. Nesse sentido, a internet traz soluções para essas dificuldades. As redes sociais digitais e os sites possibilitam a criação de ligações entre quem tem e quem precisa, e agem como intermediários nas transações. De acordo com Botsman (2013), tecnologias sociais, de mobilidade e localização são fundamentais para o consumo colaborativo. Elas tornam o ato de compartilhar mais fluido a partir da competência e da confiabilidade. É provável formar negócios que podem, de forma eficiente, conectar milhões de bens e aptidões com milhões de necessidades.

Sastre e Ikeda (2012) também evidenciam a associação do consumo colaborativo com a internet, visto que, a evolução desta possibilitou uma comunicação mais rápida entre consumidores e as organizações. Nesse cenário, a internet se apresenta como um grande espaço para o compartilhamento, que pode ser acessado por qualquer pessoa em qualquer lugar do mundo, desde que haja acesso.

Como mencionado na introdução deste estudo, Botsman e Rogers (2011) apresentam três tipos de sistemas que englobam negócios da economia colaborativa, são eles: sistema de serviços de produtos; os mercados de redistribuição; e estilo de vida colaborativo. No sistema de serviços de produtos, encontram-se os negócios que possibilitam ao consumidor utilizar um bem sem a necessidade de adquiri-lo. Dessa forma, produtos de 
propriedade de uma empresa ou de uma pessoa física podem ser compartilhados (OTA; PIÃO; MELO, 2017), como exemplo, o compartilhamento de automóveis.

No mercado de redistribuição ocorre a reutilização ou revenda de produtos, ou seja, a troca de roupas, brinquedos, livros e etc.; a exemplo, temos a plataforma Ebay, que trabalha com a revenda de produtos usados ou não. $\mathrm{O}$ último tipo, o estilo de vida colaborativo, se dá quando pessoas com interesses em comum, desejam trocar e compartilhar ativos menos tangíveis como tempo, habilidades, espaço ou dinheiro, dando origem a serviços como espaços de coworking e lojas colaborativas (BOTSMAN; ROGERS, 2011). Dentre os sistemas supracitados, Markus e Orsi (2016) afirmam que os mercados de redistribuição, seguido dos estilos de vida colaborativos apresentam um maior número de negócios na internet.

Apesar do incentivo da tecnologia e do surgimento de vários tipos de negócios relacionados à economia colaborativa, diferentes motivos, benefícios e riscos podem estar associados ao consumo colaborativo, aspectos que serão tratados no tópico a seguir.

\subsection{Motivações, beneficios e riscos associados ao consumo colaborativo}

Belk (2014) compreende o consumo colaborativo como uma forma das pessoas coordenarem a aquisição e distribuição de recursos. Com isso, a intenção desse tipo de consumo, de acordo com Andrade e Pinto (2014), é fazer com que as pessoas entendam a vantagem do acesso ao produto ao invés de detê-lo, poupando recursos, como tempo e dinheiro; aumentando sua rede de relacionamentos e gerando um entendimento sobre o tema. Assim, entre os motivos que levam as pessoas a optarem por esse tipo de consumo estão: o econômico, o consumo consciente e a valorização de hábitos sustentáveis para que ocorra menos desperdício e aumente a vida útil dos produtos, consequentemente provocando menos impacto na natureza (BOTSMAN; ROGERS, 2011).

Posteriormente, Hamari, Sjöklint e Ukkonen (2016) pesquisaram sobre as motivações intrínsecas e extrínsecas na formação de atitudes e intenções de uso associadas ao consumo colaborativo. Os resultados obtidos indicam que os motivos extrínsecos (benefícios financeiros) têm consequências sobre as pessoas e sua disponibilidade para participar em atividades de compartilhamento, sendo os motivos econômicos vistos como principal fator para o início da colaboração. Sob outra perspectiva, tem os motivos intrínsecos, por exemplo, sustentabilidade ecológica. Esse tipo de estímulo é inerente a uma pessoa que não necessita de influência externa para fazer as coisas acontecerem, assim estão mais relacionadas a atitudes.

Outro fator importante a ser considerado, é o risco associado pelos consumidores às práticas de consumo colaborativo. Isso porque as pessoas, em muitas ocasiões, receiam participar de negócios colaborativos por não ter confiança na outra parte envolvida no processo. Ao observar os princípios de Bostman e Rogers (2011) - crença no bem comum, massa crítica, capacidade ociosa e confiança entre desconhecidos -, nota-se que trata-se de elemento importante para o funcionamento do consumo colaborativo e consequentemente para diminuir o risco associado à prática.

Assim, um elemento essencial considerado como facilitador das práticas colaborativas é a confiança colocada nas relações sociais e também nas relações institucionais e organizacionais (BOTSMAN; ROGERS, 2011; HUMPHRIES; WILDING, 2004; OSTROM, 2000). Para determinar a confiança, ressalta-se algumas condições fundamentais, como o enfrentamento de riscos, compreensão de perda, a interdependência entre o interesse das partes envolvidas e a insegurança sobre a expectativa de outras partes (OSTROM, 2000).

Lamberton e Rose (2012) aprofundaram os estudos quanto à adesão dos consumidores ao uso dos sistemas compartilhados. As conclusões comprovam que, além dos custos e benefícios naturalmente vistos como base para o compartilhamento, a percepção do risco de escassez é um efeito decisivo da possibilidade de compartilhar, isto é, o consumidor não só considera a sua participação nos sistemas, bem como a participação e a demanda de uso dos outros participantes do sistema de compartilhamento.

A hipótese de Lamberton e Rose (2012) está fundamentada na teoria do risco percebido de Raymond Bauer, que defende a antecipação dos problemas por parte do consumidor e a ponderação das dúvidas na procura por opções de menor risco no processo decisório. Conforme estabelecido na teoria, os riscos ou as dúvidas geralmente vistos pelos consumidores são: o tempo preciso para a aprendizagem de uso, o tempo preciso para a aquisição, o risco psicológico e social, como o dano a pessoas, gasto financeiro e o gasto físico para a aquisição e uso.

\section{Procedimentos Metodológicos}

De acordo com Donato e Donato (2019), a Revisão Sistemática utiliza métodos explícitos para a execução de uma pesquisa bibliográfica ampla e avalia criticamente os estudos individuais. Nesse sentido, essa revisão 
responde a uma questão de pesquisa definida: que fatores influenciam o consumidor a praticar o consumo colaborativo, e é caracterizada por uma metodologia que visa compreender e interpretar o fenômeno estudado por intermédio do entendimento e perspectiva das pessoas inseridas no próprio fenômeno.

Para alcançar o objetivo geral estabelecido nesta pesquisa, iniciamos o procedimento de revisão sistemática com a seleção das bases de dados nas quais foram realizadas as buscas. Utilizamos um método estruturado de pesquisa em bases de dados eletrônicas visando identificar escritos sobre o tema. Para tal realização foram usadas como fontes de pesquisa as bases de dados: Scientific Periodicals Electronic Library - SPELL e Portal de Periódicos CAPES. A escolha da SPELL aconteceu pelo fato dessa base de dados possuir uma grande quantidade de produção acadêmica no que tange à área de Ciências Sociais Aplicadas, colaborando com a identificação de artigos que sejam capazes de auxiliar a responder aos objetivos da pesquisa. No que corresponde ao Portal de Periódicos CAPES, a preferência por essa base de dados se deu pelo fato do CAPES abranger uma quantidade expressiva de estudos nacionais, e também, por obter acesso imediato a informações científicas qualificadas.

Os critérios empregados para seleção na base SPELL foram: artigos publicados a partir de 2015, considerando-se que é um tema bastante novo quando nos referimos aos trabalhos publicados nos últimos anos. Além disso, foi possível investigar o que se vem estudando sobre o tema nos últimos 5 anos; nas áreas de conhecimento: Administração, Contabilidade, Economia, Engenharia e Turismo; no idioma português. Os termos "consumo colaborativo" ou "negócio colaborativo" ou "economia compartilhada" ou "economia colaborativa" foram buscados simultaneamente nos resumos dos artigos.

A seleção na base de dados Periódicos Capes seguiu os seguintes critérios: artigos publicados a partir de 2015, selecionados com os termos de busca: consumo colaborativo ou negócio colaborativo (busca 1); economia colaborativa ou economia compartilhada (busca 2). Foram realizadas duas buscas porque o mecanismo do Portal não permite mais de dois termos de buscas simultaneamente. O mecanismo de busca procurou esses termos em qualquer parte do artigo, na opção de termo "é (exato)", no idioma português, em periódicos revisados pelos pares. As buscas nas duas bases de dados foram realizadas no mês de junho de 2020.

Após ser feita a seleção dos artigos na base SPELL e Portal Capes, o próximo passo foi exportá-los no formato Bibtex para o software StArt, gerenciador de revisão sistemática de bibliografia. Posteriormente, com a assistência do StArt, continuamos o procedimento de seleção dos artigos. Nessa etapa, foi possível excluir os artigos apresentados em duplicidade, isto é, aqueles encontrados nas duas bases de dados, no qual um será analisado e o outro será excluído devido a sua dualidade. Após a exclusão, realizamos a leitura dos títulos e resumos dos artigos restantes. A partir dessa leitura, utilizamos como critério de inclusão para manutenção do artigo na revisão sistemática: artigos que de alguma forma tratavam sobre a questão de pesquisa. E como critério de exclusão, aqueles artigos que não tratavam sobre a questão de pesquisa.

Logo após essa etapa foi feita a leitura da introdução e conclusão dos artigos. Nesse momento, foram mantidos na revisão sistemática os trabalhos que atenderam os seguintes critérios de inclusão: artigos que tratavam de alguma forma sobre os objetivos específicos desta pesquisa: motivos, benefícios e riscos que os consumidores associam à prática de consumo colaborativo; artigos disponíveis na íntegra. Foram excluídos da revisão os artigos que não atenderam aos critérios de inclusão.

A etapa seguinte foi realizar a leitura completa dos artigos que atenderam aos critérios de inclusão das etapas já mencionadas. Nesta leitura foram observados os seguintes critérios de qualidade/inclusão: periódico de publicação do artigo no mínimo B2; estudos com referência bibliográfica relevante/atual para a temática da pesquisa (na maioria dos últimos cinco anos, ou seja, a partir de 2015) e estudos que apresentaram uma metodologia clara/explícita. Os artigos que não atenderam aos critérios de qualidade foram excluídos da revisão sistemática. No Quadro 1 apresentamos uma síntese dos procedimentos adotados para a seleção dos artigos.

Após a última etapa mencionada, foram definidos os artigos utilizados para a extração das informações que respondem aos objetivos específicos da pesquisa, ou seja, informam sobre os motivos, benefícios e riscos associados pelos consumidores à prática de consumo colaborativo. 
Quadro 1 - Procedimentos da revisão sistemática.

\begin{tabular}{|c|c|c|}
\hline \multicolumn{3}{|c|}{ Questão de pesquisa: Que fatores influenciam o consumidor a praticar o consumo colaborativo? } \\
\hline $\begin{array}{l}\text { Critérios iniciais de seleção na } \\
\text { base de dados } S P E L L\end{array}$ & \multicolumn{2}{|c|}{$\begin{array}{l}\text { Artigos publicados a partir de } 2015 \text {, selecionados com os termos de busca: consumo } \\
\text { colaborativo ou negócio colaborativo ou economia compartilhada ou economia } \\
\text { colaborativa. O mecanismo de busca da base de dados SPELL buscou esses termos } \\
\text { no resumo dos artigos, nas áreas de conhecimento: Administração, Contabilidade, } \\
\text { Economia, Engenharia e Turismo, e idioma português. }\end{array}$} \\
\hline $\begin{array}{l}\text { Critérios iniciais de seleção na } \\
\text { base de dados Portal de Periódicos } \\
\text { Capes }\end{array}$ & \multicolumn{2}{|c|}{$\begin{array}{l}\text { Artigos publicados a partir de } 2015 \text {, selecionados com os termos de busca: consumo } \\
\text { colaborativo ou negócio colaborativo (busca 1); economia colaborativa ou economia } \\
\text { compartilhada (busca 2). O mecanismo de busca da base de dados CAPES buscou } \\
\text { esses termos em qualquer parte do artigo - com o termo é exato, desde } 2015 \text {, em } \\
\text { português, de periódicos revisados pelos pares. }\end{array}$} \\
\hline Leitura 1 - título e resumo & $\begin{array}{l}\text { Critério de inclusão: } \\
\text { - Artigos que de alguma forma tratavam } \\
\text { sobre a questão de pesquisa. }\end{array}$ & $\begin{array}{l}\text { Critério de exclusão: } \\
\text { - Artigos duplicados; } \\
\text { - Artigos que não tratavam sobre a } \\
\text { questão de pesquisa. }\end{array}$ \\
\hline Leitura 2 - Introdução e conclusão & $\begin{array}{l}\text { Critério de inclusão: } \\
\text { - Artigos que tratavam de alguma forma } \\
\text { sobre os objetivos específicos desta } \\
\text { pesquisa - motivos, benefícios e riscos } \\
\text { que os consumidores associam à prática } \\
\text { de consumo colaborativo; } \\
\text { - Artigos disponíveis na íntegra. }\end{array}$ & $\begin{array}{l}\text { Critério de exclusão: } \\
\text { - Artigos que não tratavam de } \\
\text { alguma forma sobre os objetivos } \\
\text { específicos desta pesquisa; } \\
\text { - Trabalhos que não estejam } \\
\text { disponíveis na íntegra. }\end{array}$ \\
\hline Leitura 3 - trabalho completo & $\begin{array}{l}\text { Critérios de qualidade e inclusão: } \\
\text { - O periódico de publicação do artigo é no } \\
\text { mínimo B2; } \\
\text { - Estudos com referência } \\
\text { bibliográfica/atual para a temática da } \\
\text { pesquisa (na maioria dos últimos cinco } \\
\text { anos, ou seja, a partir de 2015); } \\
\text { - O estudo apresenta uma metodologia } \\
\text { clara/explícita. }\end{array}$ & $\begin{array}{l}\text { Critério de exclusão: } \\
\text { - Artigos que não atenderam aos } \\
\text { critérios de qualidade. }\end{array}$ \\
\hline Leitura 4 - trabalho completo & \multicolumn{2}{|c|}{$\begin{array}{l}\text { Extração nos artigos selecionados de informações que respondem aos três últimos } \\
\text { objetivos específicos da pesquisa. }\end{array}$} \\
\hline
\end{tabular}

Fonte: Elaborado pelas autoras (2020).

\section{Resultados}

\subsection{Seleção dos artigos da revisão sistemática}

Diante dos procedimentos adotados na pesquisa, nesta seção serão exibidos os resultados relacionados às etapas da revisão sistemática, isto é, referentes à busca, leitura, seleção e por fim, avaliação dos artigos a serem utilizados para a extração das informações que respondem aos objetivos da pesquisa.

No Quadro 2, apresentamos os termos de busca, critérios de seleção e resultados da busca nas bases de dados escolhidas. Como resultado foram selecionados 38 artigos na base SPELL e 41 na CAPES, totalizando 79 artigos encontrados. 
Quadro 2 - Resultado da busca nas bases de dados

\begin{tabular}{|c|c|c|c|}
\hline Portal & Termos de buscas & Critérios de seleção & Resultado \\
\hline SPELL & $\begin{array}{l}\text { Consumo Colaborativo ou } \\
\text { Economia Compartilhada ou } \\
\text { Economia Colaborativa ou } \\
\text { Negócio Colaborativo }\end{array}$ & $\begin{array}{l}\text { - Período de publicação: A partir de 2015; } \\
\text { - Idioma: Português; } \\
\text { - Tipo de documento: Artigos. }\end{array}$ & 38 \\
\hline \multirow{3}{*}{ CAPES } & $\begin{array}{l}\text { Consumo colaborativo OR Negócio } \\
\text { colaborativo }\end{array}$ & \multirow[t]{2}{*}{$\begin{array}{l}\text { - Período de publicação: a partir de 2015; } \\
\text { - Idioma: Português; } \\
\text { - Tipo de documento: Artigos. }\end{array}$} & 17 \\
\hline & $\begin{array}{l}\text { Economia compartilhada } \mathrm{OR} \\
\text { Economia colaborativa }\end{array}$ & & 24 \\
\hline & \multicolumn{2}{|c|}{ TOTAL DE ARTIGOS } & 79 \\
\hline
\end{tabular}

Fonte: Elaborado pelas autoras (2020).

Após as buscas, os 79 artigos encontrados foram exportados para o software StArt, que atua como um gerenciador de revisões sistemáticas, com objetivo de organizar os trabalhos de maneira a facilitar sua classificação. Com a utilização do StArt, observamos que os estudos encontrados na base SPELL correspondem a $48 \%$ (38) dos artigos, em contrapartida, os estudos identificados no Portal Capes foram um total de $52 \%$ (41 artigos). Isto demonstra um equilíbrio no número de trabalhos encontrados nas duas bases de dados.

Além disso, através do software StArt, foi possível verificar também os estudos duplicados, presentes nas duas bases de dados utilizadas. Com base nessa informação, foram excluídos 18 artigos do processo de seleção dos estudos. Na etapa seguinte, foi realizada a leitura dos títulos e resumos dos artigos. Considerando os critérios de inclusão e exclusão adotados, podemos ver no Quadro 3 que continuaram na revisão sistemática 23 artigos da base dados SPELL e 9 artigos do Portal CAPES.

Quadro 3 - Leitura dos títulos e resumos - SPELL e Portal CAPES

\begin{tabular}{|c|c|c|c|}
\hline Critérios de inclusão & Critérios de exclusão & Base de dados & $\begin{array}{c}\mathrm{N}^{0} \text { artigos } \\
\text { selecionados }\end{array}$ \\
\hline \multirow{2}{*}{$\begin{array}{l}\text { - Artigos que de alguma forma } \\
\text { tratavam sobre a questão de } \\
\text { pesquisa. }\end{array}$} & \multirow{2}{*}{$\begin{array}{l}\text { - Artigos duplicados; } \\
\text { - Artigos que não tratavam sobre a } \\
\text { questão de pesquisa. }\end{array}$} & SPELL & 23 \\
\hline & & Portal Capes & 9 \\
\hline \multicolumn{3}{|c|}{ TOTAL } & 32 \\
\hline
\end{tabular}

Fonte: Elaborado pelas autoras (2020).

$\mathrm{Na}$ etapa seguinte realizamos a leitura das introduções e conclusões. Como resultado, considerando-se os critérios de inclusão e exclusão, foram excluídos sete artigos da análise e mantidos 25 , conforme apresentado no Quadro 4 a seguir.

Quadro 4 - Leitura das introduções e conclusões - SPELL e Portal CAPES

\begin{tabular}{|c|c|c|c|}
\hline Critérios de inclusão & Critérios de exclusão & Base de dados & $\begin{array}{c}\mathrm{N}^{0} \text { artigos } \\
\text { selecionados }\end{array}$ \\
\hline \multirow{2}{*}{$\begin{array}{l}\text { - Artigos que respondem à questão de } \\
\text { pesquisa (motivos, benefícios e riscos } \\
\text { que os consumidores associam à prática } \\
\text { de consumo colaborativo); } \\
\text { - Artigos disponíveis na íntegra. }\end{array}$} & \multirow{2}{*}{$\begin{array}{l}\text { - Artigos que não tragam } \\
\text { informação sobre a questão } \\
\text { de pesquisa; } \\
\text { - Trabalhos que não estejam } \\
\text { disponíveis na íntegra. }\end{array}$} & SPELL & 21 \\
\hline & & Portal Capes & 4 \\
\hline \multicolumn{3}{|c|}{ TOTAL } & 25 \\
\hline
\end{tabular}

Fonte: Elaborado pelas autoras (2020).

Por fim, foi realizada a leitura dos artigos por completo, e observando os critérios de qualidade estabelecidos, selecionamos 13 artigos que fizeram parte da etapa de extração das informações, conforme demonstrado no Quadro 
5.

Quadro 5 - Leitura dos artigos na íntegra - SPELL e Portal CAPES

\begin{tabular}{|c|c|c|}
\hline Critérios de qualidade & Base de dados & $\begin{array}{c}\mathrm{N}^{0} \text { artigos } \\
\text { selecionados }\end{array}$ \\
\hline \multirow{2}{*}{$\begin{array}{l}\text { - O periódico de publicação do artigo é no mínimo B2; } \\
\text { - Estudos com referência bibliográfica relevante/atual para a temática da } \\
\text { pesquisa em estudo (na maioria dos últimos cinco anos, ou seja, a partir de } \\
2015 \text { ); } \\
\text { - O estudo apresenta uma metodologia clara/explícita. }\end{array}$} & SPELL & 11 \\
\hline & Portal Capes & 2 \\
\hline \multicolumn{2}{|l|}{ TOTAL } & 13 \\
\hline
\end{tabular}

Fonte: Elaborado pelas autoras (2020).

A seguir, no Quadro 6 apresentamos os títulos e autores dos artigos que foram selecionados para a revisão sistemática após a aplicação dos critérios de qualidade.

Quadro 6 - Artigos selecionados para a revisão sistemática

\begin{tabular}{|c|c|}
\hline Títulos & Autores \\
\hline $\begin{array}{l}\text { 1- Crowdfunding: A influência da co-criação e do sentimento de pertença na } \\
\text { satisfação dos apoiadores luso-brasileiros }\end{array}$ & Bernardes e Lucian (2015) \\
\hline 2- Consumo colaborativo e valores pessoais: o caso da bicicleta compartilhada & Arruda et al. (2016) \\
\hline $\begin{array}{l}\text { 3- Turismo, viagem e economia compartilhada: as experiências relatadas pelos } \\
\text { usuários do couchsurfing em Natal/RN }\end{array}$ & Bezerra e Ferreira (2018) \\
\hline $\begin{array}{l}\text { 4- Crowdfunding: análise dos comportamentos de satisfação e lealdade dos } \\
\text { consumidores brasileiros em contexto de produtos culturais }\end{array}$ & Bernardes, Lucian e Abreu (2018) \\
\hline $\begin{array}{l}\text { 5- Percepção de gestores de hospedagens sobre plataformas de aluguel on-line por } \\
\text { temporada }\end{array}$ & Ferreira et al. (2017) \\
\hline 6- Um estudo do consumo colaborativo no Brasil e nos Estados Unidos da América & MarKus e Orsi (2016) \\
\hline $\begin{array}{l}\text { 7- Uma nova configuração do trabalho: análise interpretativa da literatura de } \\
\text { coworking }\end{array}$ & Nakao e Mussi (2018) \\
\hline $\begin{array}{l}\text { 8- Concreto ou abstrato? Um esquema conceitual das representações mentais da } \\
\text { economia compartilhada }\end{array}$ & Sordi, Petrini e Sampaio (2019) \\
\hline $\begin{array}{l}\text { 9- A economia compartilhada como um movimento de transição para uma } \\
\text { mobilidade sustentável }\end{array}$ & Pereira e Silva (2018) \\
\hline $\begin{array}{l}\text { 10- Hospitalidade e Intenção de recompra na Economia Compartilhada: um estudo } \\
\text { com equações estruturais em meios de hospedagem alternativos }\end{array}$ & Pinotti e Moretti (2018) \\
\hline $\begin{array}{l}\text { 11- Comportamento do Consumidor na Economia Compartilhada no Turismo: um } \\
\text { estudo sobre o CouchSurfing e o AirBnb }\end{array}$ & Vera e Gosling (2018) \\
\hline $\begin{array}{l}\text { 12- Economia Compartilhada no turismo: Uma discussão teórica sobre o consumo } \\
\text { colaborativo e o compartilhamento. }\end{array}$ & Vera e Gosling (2017) \\
\hline $\begin{array}{l}\text { 13- Couch, dicas e companhia: mobilidades construídas e práticas de consumo } \\
\text { colaborativo entre mulheres mediadas pelo Facebook }\end{array}$ & Silva (2019) \\
\hline
\end{tabular}

Fonte: Elaborado pelas autoras (2020).

Concluída a etapa de seleção, apresentamos nos tópicos a seguir o resultado da extração das informações quanto aos motivos, riscos e benefícios associados pelos consumidores ao consumo colaborativo.

\subsection{Motivos que levam os consumidores a adotar práticas de consumo colaborativo}

Ao analisar os artigos foi possível verificar que o consumo colaborativo é visto como um fenômeno econômico e social que aponta para o caminho da sustentabilidade como principal motivo de práticas colaborativas, visto que reduz a poluição ambiental e economiza recursos financeiros (SORDI; PETRINI; SAMPAIO, 2019). Já Silva (2019) afirma que o fator ambiental é o principal motivo gerado pelo compartilhamento que impacta positivamente no bem-estar social e no meio ambiente visto que os consumidores recorrem a esse tipo de consumo com o propósito de serem produtivos, capazes de consumir menos e de forma mais sustentável. 
De acordo com Vera e Gosling (2018), a economia de custos é uma das motivações para as pessoas se engajarem em práticas de consumo ligadas à economia compartilhada. As autoras também apontam que este consumo contribui para o bem-estar social, considerando-se que a colaboração não visa lucros, mas sim, a satisfação das necessidades de ambas as partes.

Já de acordo com Markus e Orsi (2016), a motivação pode variar de economia de recursos como dinheiro, tempo e espaço até convivência com pessoas desconhecidas, e este contato pode proporcionar novas amizades ou parcerias profissionais. Também foi mencionado que a valorização das práticas sustentáveis é um fator fundamental, no interesse de diminuir o desperdício e prolongar a vida útil dos produtos, provocando menos impacto no meio ambiente.

Outro motivo apontado para a prática do consumo colaborativo foi a possibilidade de construção de vínculos sociais. Isso corresponde à expectativa de aproximação das pessoas, criando um vínculo e sentimento de solidariedade. A prática do consumo colaborativo auxilia também a criar um senso de confiança entre os pares, proporcionando que os vínculos ultrapassem apenas os interesses econômicos e se tornem sociais (VERA; GOSLING, 2018). No Quadro 7, apresentamos os motivos identificados.

Ao analisar os artigos percebemos que vários são os motivos que levam à prática do consumo colaborativo. Podemos dizer que estes motivos são complementares, uma vez que esses consumos impactam ao mesmo tempo no bem-estar social e no compartilhamento de práticas sustentáveis. Isto ocorre em decorrência dos consumidores terem como propósito reduzir consumo de forma consciente, o que, consequentemente, resulta em redução de custos. Assim, podemos dizer que esses fatores (social, ambiental e econômico), quando relacionados ao consumo colaborativo ocorrem concomitantemente.

Os motivos identificados nos artigos selecionados nesta revisão sistemática estão de acordo com aqueles apontados nos trabalhos de Botsman e Rogers (2011) e Hamari, Sjöklint e Ukkonen (2016) que salientam os fatores econômicos e a questão da sustentabilidade como motivos para o consumo colaborativo. Já o fator social encontrado, que ressalta a construção de vínculos sociais, não havia sido observado na revisão de literatura.

Quadro 7 - Motivos que levam à prática do consumo colaborativo

\begin{tabular}{|c|c|c|}
\hline Fator & $\begin{array}{l}\text { Motivos } \\
\end{array}$ & $\begin{array}{c}\text { Autores } \\
\end{array}$ \\
\hline Ambiental & $\begin{array}{l}\text { - Contribui para a sustentabilidade ambiental; } \\
\text { - Valoriza práticas sustentáveis no desejo de } \\
\text { desperdiçar menos e aumentar a vida útil dos } \\
\text { produtos; } \\
\text { - Contribui para o consumo consciente; } \\
\text { - Resposta ao movimento do hiperconsumo. }\end{array}$ & $\begin{array}{l}\text { Nakao e Mussi (2018); Sordi; Petrini e } \\
\text { Sampaio (2019); Pinotti e Amaral (2018); } \\
\text { Pereira e Silva (2018). }\end{array}$ \\
\hline Social & $\begin{array}{l}\text { - Contribui para o bem-estar social; } \\
\text { - Construção de vínculos sociais. }\end{array}$ & Vera e Gosling (2018) \\
\hline Econômico & $\begin{array}{l}\text { - Relação custo/benefício; } \\
\text { - Economia, redução de custos; } \\
\text { - Aumento do lucro; } \\
\text { - Obtenção de renda extra. }\end{array}$ & $\begin{array}{l}\text { Markus e Orsi (2016); Vera e Gosling (2018); } \\
\text { Sordi, Petrini e Sampaio (2019); Nakao e } \\
\text { Mussi (2018). }\end{array}$ \\
\hline
\end{tabular}

Fonte: Elaborado pelas autoras (2020).

\subsection{Riscos associados pelos consumidores ao consumo colaborativo}

Como pode ser observado no Quadro 8, dois tipos de riscos associados ao consumo colaborativo foram encontrados. O primeiro refere-se ao risco de perda de recursos monetários e danos. A esse respeito, Vera e Gosling (2018) e Sordi, Petrini e Sampaio (2019) identificaram os riscos associados a perdas ou danos nas práticas de consumo colaborativo dependendo de como o compartilhamento é negociado. Conforme os autores, isso acontece, na sua maioria, em compras on-line, quando os consumidores têm a opção de escolherem em uma ampla vitrine de produtos e serviços. Nesses momentos de escolha esses indivíduos podem sofrer golpes, tendo suas informações confidenciais como dados bancários ou número do cartão de crédito clonados.

O outro risco destacado refere-se à falta de confiança em relação ao compartilhamento com estranhos. Para Sordi, Petrini e Sampaio (2019), o compartilhamento está sujeito a riscos por pessoas mal intencionadas, como em qualquer outro tipo de consumo. Os autores destacam que, principalmente quando as trocas são exclusivamente virtuais, os riscos de fraudes aumentam devido às páginas clonadas. 
O consumo colaborativo pode ser uma barreira para os consumidores, visto que é algo inovador e muitos ainda têm receio de lidar diretamente com pessoas estranhas. O medo do desconhecido ainda pode ser um problema para este tipo de consumo conquistar adeptos (PEREIRA; SILVA, 2018). Nesse sentido, Botsman e Rogers (2011) salientam a importância da confiança entre as partes envolvidas no consumo colaborativo para reduzir os riscos associados a essa prática. Desta forma, estabelecer uma relação de confiança é um aspecto que precisa ser observado pelas empresas que operam na economia colaborativa.

Quadro 8-Riscos associados ao consumo colaborativo

\begin{tabular}{|l|l|}
\hline \multicolumn{1}{|c|}{ Riscos } & \multicolumn{1}{|c|}{ Autores } \\
\hline Risco de perda de recursos monetários e danos & $\begin{array}{l}\text { Vera e Gosling (2018); Sordi, Petrini e } \\
\text { Sampaio (2019) }\end{array}$ \\
\hline Falta de confiança em relação ao compartilhamento com estranhos & Pereira e Silva (2018) \\
\hline
\end{tabular}
Fonte: Elaborado pelas autoras (2020).

\subsection{Beneficios associados pelos consumidores ao consumo colaborativo}

Com base nos artigos pesquisados, em relação aos benefícios que os consumidores associam ao consumo colaborativo, ficou evidente que o principal deles é a economia. Este resultado confirma o que Lamberton e Rose (2012) propuseram sobre a economia de custos ser um dos principais benefícios da prática do consumo colaborativo.

Já de acordo com Sordi, Petrini e Sampaio (2019), a redução de desperdícios de recursos naturais é um dos principais benefícios do consumo colaborativo. Isso se deve ao fato de que este novo modelo de negócio permite que mais pessoas possam utilizar um mesmo bem ou serviço.

Ainda em termos dos benefícios identificados pelos consumidores, fica evidente que a economia compartilhada apresenta um caminho para a sustentabilidade, isso porque a colaboração propõe um consumo mais consciente, apoiado nas três dimensões da sustentabilidade, respectivamente, econômico, social e ambiental: provocando benefícios econômicos; buscando a composição do capital social; reduzindo o consumo e a geração de resíduos (PEREIRA; SILVA, 2018). Neste sentido, segundo os autores, um benefício apontado pelos consumidores é que o consumo colaborativo desperta a consciência ambiental.

A praticidade em acesso aos bens e a contenção de despesas são benefícios do consumo colaborativo. Isso se justifica pelo fato de que os consumidores preferem ter alcance a serviços e produtos temporariamente, sem que ocorra a necessidade de comprá-los. Este tipo de consumo beneficia aqueles compradores que estão à procura de maior comodidade e menor preço (FERREIRA et al., 2017).

Por fim, Nakao e Mussi (2018) afirmam que o consumo colaborativo beneficia ambas as partes do compartilhamento; o produtor que terá a capacidade de fornecer produtos e serviços de maneira eficiente, e o consumidor que será capaz de ter o acesso apenas, e não, necessariamente, a propriedade. No Quadro 9, vemos os benefícios identificados nos artigos.

Quadro 9-Benefícios associados ao consumo colaborativo

\begin{tabular}{|l|l|}
\hline \multicolumn{1}{|c|}{ Benefício } & \multicolumn{1}{|c|}{ Autores } \\
\hline $\begin{array}{l}\text { Benefício econômico (ajuda financeira, economia de } \\
\text { dinheiro, diminuição de custos) }\end{array}$ & $\begin{array}{l}\text { Vera e Gosling (2018); Sordi, Petrini e Sampaio (2019); } \\
\text { Pinotti e Moretti (2018); Nakao e Mussi (2018); Ferreira } \text { et } \\
\text { al. (2017) }\end{array}$ \\
\hline Desperta a consciência socioambiental & Pereira e Silva (2018) \\
\hline Evita/reduz o desperdício de recursos naturais & $\begin{array}{l}\text { Sordi, Petrini e Sampaio (2019); } \\
\text { Pereira e Silva (2018) }\end{array}$ \\
\hline Praticidade em acesso aos bens & Ferreira et al. (2017) \\
\hline
\end{tabular}

Fonte: Elaborado pelas autoras (2020).

\section{Conclusões}

Nesta revisão sistemática da literatura foi possível concluir que ocorreu um equilíbrio em relação à quantidade de estudos apresentados nas duas bases de dados escolhidas. Porém, os artigos selecionados na base de dados SPELL apresentaram um maior número de estudos que se encaixaram nos critérios da pesquisa. Apesar de partimos de 79 artigos, apenas treze trouxeram informações pertinentes aos objetivos específicos, o que demonstra que na academia brasileira, a partir de 2015 , poucos trabalhos discutiram sobre os motivos, benefícios e riscos associados 
ao consumo colaborativo.

Quanto aos fatores que influenciam os consumidores à prática do consumo colaborativo, observamos que os motivos identificados podem ser classificados em fatores econômicos, sociais e ambientais. Entre esses, identificamos que o fator ambiental foi o motivo mais apontado pelos consumidores pesquisados nos artigos estudados, o que pode apontar para uma maior consciência ambiental por parte desses consumidores. É importante destacar que entre os motivos encontrados nos artigos analisados, foi identificado o fator social, que ressalta a construção de vínculos sociais. Este fator não havia sido observado na revisão de literatura.

Entre os benefícios, salientamos que o econômico foi o mais mencionado nos artigos incluídos nesta revisão sistemática. Isto pode demonstrar que o consumo colaborativo além de trazer benefícios ambientais pode impactar no aspecto financeiro desses consumidores, trazendo redução de custos. Quanto aos riscos, além do monetário, os riscos identificados estão relacionados à prática de consumo colaborativo mediada pela internet. Nesse caso, os consumidores identificam como risco a perda de dados pessoais confidenciais ou ainda ser alvo de golpes. Efetuar o compartilhamento com estranhos também é considerado um risco para os consumidores. Com base nesses resultados, concluímos que os motivos, benefícios e riscos identificados nos artigos selecionados nesta revisão sistemática da literatura acadêmica brasileira, de modo geral, correspondem àqueles apontados na literatura sobre consumo colaborativo.

Sugerimos para novos estudos, investigar, por meio de entrevista ou questionário, os fatores que influenciam o consumidor de diferentes sistemas de consumo colaborativo: sistema de serviços de produtos; mercado de redistribuição e estilos de vida colaborativos, de forma que seja possível comparar se tais fatores são os mesmos, e quais têm maior influência sobre o consumidor. Neste sentido, também pode haver diferenças entre práticas de consumo colaborativo que envolvem o compartilhamento de bens e aquelas que envolvem apenas serviços.

\section{Referências}

AGÊNCIA GLOBO. Compartilhamento deverá ser 30\% do PIB de serviços. Revista Época Negócios. Out., 2017. Disponível em: https://epocanegocios.globo.com/Economia/noticia/2017/10/compartilhamento-deveraser-30-do-pib-de-servicos.html. Acesso em: 19 fev. 2020.

ALGAR, R. Collaborative consumption. Leisure Report, 2007. Disponível em: https://www.oxygenconsulting.co.uk/insights/collaborative-consumption/. Acesso em: 10 jan. 2020.

ANDRADE, H. G. C.; PINTO, M. R. O que é meu é seu?! Seria o consumo colaborativo uma inovação social? In: ENCONTRO NACIONAL DE ESTUDOS DO CONSUMO, 07., 2014, Rio de Janeiro. Anais [...]. Rio de Janeiro: Instituto de Ciências Humanas e Filosofia (ICHF) Bloco P - Campus do Gragoatá, 2014. Disponível em: http://www.estudosdoconsumo.com.br/artigosdoenec/ENEC2014-GT08. Acesso em: 10 mar. 2020.

BARBIERI, N. N. Consumo colaborativo em uma plataforma de social commerce: estudo de caso do site de compras e vendas Enjoei. 2015. Trabalho de Conclusão de Curso (Bacharelado em Comunicação Social - Publicidade e Propaganda) - Faculdade de Biblioteconomia e Comunicação, Universidade Federal do Rio Grande do Sul, Porto Alegre, 2015. Disponível em: https://lume.ufrgs.br/bitstream/handle/10183/122688/000971249.pdf?sequence=1\&isAllowed=y. Acesso em: 10 jan. 2020.

BARDHI, F.; ECKHARDT, G. M. Access-based consumption: the case of car sharing. Journal of Consumer Research, v. 39, n. 4, p. 881-898, 2012. Disponível em: https://www.researchgate.net/publication/259711186_Access-

Based_Consumption_The_Case_of_Car_Sharing. Acesso em: 10 mar. 2020.

BELK, R. Possessions and the extended self. Journal of consumer research, v. 15, n. 2, p. 139-168, 1988. Disponível em: https://academic.oup.com/jcr/article/15/2/139/1841428. Acesso em: 10 fev. 2020.

BELK, R. Sharing. Journal of Consumer Research, v. 36, n. 5, p. 715-734, 2010. Disponível em: https://academic.oup.com/jcr/article-abstract/36/5/715/1786743? redirected From=full text. Acesso em: 11 fev. 2020

BELK, R. A tendência mundial do consumo colaborativo. 2013. Disponível em: http:// www.revistawide.com.br/marketing/a-tendencia-mundial-do-consumo-colaborativo. Acesso em: 10 fev. 2020. 
BELK, R. You are what you can access: sharing and collaborative consumption online. Journal of Business Research, [s.1.], v. 67, n. 8, p.1595-1600, ago. 2014. Disponível em: https://www.sciencedirect.com/science/article/abs/pii/S0148296313003366. Acesso em: 11 fev. 2020.

BOTSMAN, R. The sharing economy lacks a shared definition. 2013. Disponível em: https://rachelbotsman.com/work/the-sharing-economy-lacks-a-shared-definition-fastco-exist/. Acesso em: 19 fev. 2020.

BOTSMAN, R.; ROGERS, R. O que é meu é seu: como o consumo colaborativo vai mudar o nosso mundo. Porto Alegre: Bookman, 2011.

CHOI, H. R.; CHO, M. J.; LEE, K.; HONG, S. G.; WOO, C. R. The business model for the sharing economy between SMEs. WSEAS Transactions on Business and Economics, 2014. Disponível em: https://pdfs.semanticscholar.org/b700/6c2a885dce85e50be307308dd9944dffb296.pdf?_ga=2.38842147. 1485396915.1586280809-1517865247.1584648515. Acesso em: 19 fev. 2020.

COUTINHO, F. G. A. Consumo colaborativo: o compartilhamento de produtos e serviços que está modificando os negócios no Brasil. In: CONGRESSO BRASILEIRO DE CIÊNCIAS DA COMUNICAÇÃO, XXXVIII., 2015, Rio de Janeiro, RJ. Anais [...]. Rio de Janeiro: UFRJ, 2015. Disponível em: https://docplayer.com.br/3113253-Consumo-colaborativo-o-compartilhamento-de-produtos-e-servicosque-esta-modificando-os-negocios-no-brasil-1.html. Acesso em: 11 fev. 2020.

DONATO, H; DONATO, M. Etapas na Condução de uma Revisão Sistemática. Acta Med Port, v. 32, n.3, p. 227 235, mar. 2019. DOI: https://doi.org/10.20344/amp.11923. Disponível em: /1192https://www.actamedicaportuguesa.com/revista/index.php/amp/article/view3. Acesso em: 14 jun. 2020.

FAJARDO, E. Consumo consciente, comércio justo: conhecimento e cidadania como fatores econômicos. Rio de Janeiro: Senac Nacional, 2010.

FARAH, E. Consumo colaborativo na moda: um estudo sobre as motivações e barreiras da participação em serviços de guarda-roupas compartilhados. 2019. Dissertação (Mestrado Profissional em Administração com ênfase em Comportamento do Consumidor) - Programa de Mestrado Profissional e Comportamento do Consumidor, Escola Superior de Propaganda e Marketing, São Paulo, 2019. Disponível em: https://pesquisa.espm.br/wp-content/uploads/2019/05/mpcc2019-eva-farah.pdf. Acesso em: 10 fev. 2020.

FERREIRA, K. M.; SANTOS, R. A. D.; MÉXAS, M. P.; MEIRIÑO, M. J. Percepção de gestores de hospedagens sobre plataformas de aluguel on-line por temporada. Turismo: Visão e Ação, v. 19, n. 3, p. 658-683, 2017. Disponível em: https://siaiap32.univali.br/seer/index.php/rtva/article/view/11675. Acesso em: 16 jun. 2020.

HAMARI, J.; SJÖKLINT, M.; UKKONEN, A. The sharing economy: why people participate in collaborative consumption. Journal of the association for information Science and Technology. v. 67, n. 9, p. 2047 2059. $2016 . \quad$ Sep. Disponível em: https://www.researchgate.net/publication/255698095_The_Sharing_Economy_Why_People_Participate in_Collaborative_Consumption. Acesso em: 11 mar. 2020.

HUMPHRIES, A. S.; WILDING, R. D. Long term collaborative business relationships: the impact of trust and behaviour. Journal of Marketing Management, v. 20, p. 1107-1122, 2004. Disponível em: https://pdfs.semanticscholar.org/a54b/14aad6bbf3110903e522ccb9f8aef5be5995.pdf. Acesso em: 11 mar. 2020.

LAMBERTON C. P.; ROSE R. L. When is ours better than mine? A framework for understanding and altering participation in commercial sharing systems. Journal of Marketing, v. 76, n. 4, p. 109-125, 2012. Disponível em: https://www.semanticscholar.org/paper/When-is-Ours-Better-Than-Mine-A-Frameworkfor-and-Lamberton-Rose/fecc69f733acb76e058cf3ac698eab6fc2b9becb. Acesso em: 11 mar. 2020.

MARKUS, K.; ORSI, D. F. O. Um estudo do consumo colaborativo no Brasil e nos Estados Unidos da América. Revista Organizações em Contexto, v. 12, n. 24, p. 117-129, 2016. Disponível em: https://www.metodista.br/revistas/revistas-metodista/index.php/OC/article/view/6477/pdf_1. Acesso em: 10 fev. 2020.

MENDES, F. S.; CEROY, F. M. Economia compartilhada e a política nacional de mobilidade urbana: uma 
proposta de marco legal. Brasília: Núcleo de Estudos e Pesquisas/ CONLEG/Senado, Novembro/2015 (Texto para Discussão $\mathrm{n}^{\mathrm{o}}$ 185). Disponível em: https://www12.senado.leg.br/publicacoes/estudoslegislativos/tipos-de-estudos/textos-para-discussao/td185. Acesso em: 10 fev. 2020.

NAKAO, B; MUSSI, C. C. Uma nova configuração do trabalho: análise interpretativa da literatura de coworking. Contextus - Revista Contemporânea de Economia e Gestão, v. 16, n. 2, p. 53-89, 2018. Disponível em: $\quad$ http://www.spell.org.br/documentos/ver/50279/uma-nova-configuracao-dotrabalho\%E2\%80\%93analise-interpretativa-da-literatura-de-coworking-. Acesso em: 17 jun. 2020.

OLSON, M. The logic of collective action: public goods and the theory of groups. Cambridge, MA: Harvard University Press, $1965 . \quad$ Disponível em: https://www.researchgate.net/publication/226965061_Logic_of_Collective_Action. Acesso em: 11 mar. 2020.

OSTROM, E. Collective action and the evolution of social norms. The Journal of Economic Perspectives, v. 14, n. 3, p. 137-158, 2000. Disponível em: https://www.aeaweb.org/articles?id=10.1257/jep.14.3.137. Acesso em: 9 mar. 2020.

ORNELLAS, R. S. O consumo colaborativo de transporte individual Car Sharing e o processo decisório do consumidor na cidade de São Paulo. 2012. Dissertação (Mestrado em Ciências) - Faculdade de Economia, Administração e Contabilidade, Universidade de São Paulo, São Paulo, 2012. Disponível em: https://teses.usp.br/teses/disponiveis/12/12139/tde-17042013184453/publico/ReginadaSilvaOrnellas.pdf. Acesso em: 11 fev. 2020.

OTA, B.; PIÃO, R.; MELO, M. Uma análise do modelo de negócios de empresas de economia compartilhada. In: XX SEMEDAD/ Seminário em administração. 2017. Disponível em: https://idonline.emnuvens.com.br/id/article/view/1438. Acesso em: 10 mar. 2020.

PEREIRA, C. H. T.; SILVA. M. E. A economia compartilhada como um movimento de transição para uma mobilidade sustentável. Revista de Gestão Ambiental e da Sustentabilidade, v. 7, n. 3, p. 451-468, set./dez. $2018 . \quad$ Disponível em: https:/dialnet.unirioja.es/servlet/articulo;jsessionid=560B95EA0EBD0D4E9A1209C751E1B821.dialne t02? codigo $=6786922$. Acesso em: 16 jun. 2020.

SASTRE, P. T. N.; IKEDA, A. A. Reflexões sobre consumo colaborativo. In: ENCONTRO DA ANPAD, XXXVI., 2012, Rio de Janeiro. Anais [...]. Rio de Janeiro: Windsor Barra Hotel \& Congressos, 2012. p. 1-10. Disponível em: http://legado.fucape.br/_public/producao_cientifica/2/admin-pdf2017 EnANPAD_MKT117.pdf. Acesso em: 10 jan. 2020.

SILVA, T. Couch, dicas e companhia. Revista Turismo em Análise, v. 30, n. 1, p. 46-59, jan./abr. 2019. Disponível em: http://www.revistas.usp.br/rta/article/view/146152/157343. Acesso em: 16 jun. 2020.

SORDI, J.; PETRINI, M.; SAMPAIO, C. H. Concreto ou abstrato? Um esquema conceitual das representações mentais da economia compartilhada. Teoria e Prática em Administração, v. 9, n. 1, p. 105-118, 2019. Disponível em: https://periodicos.ufpb.br/ojs2/index.php/tpa/article/view/42078/22339. Acesso em: 16 jun. 2020.

VERA, L. A. R.; GOSLING, M. S. Comportamento do consumidor na economia compartilhada no turismo: um estudo sobre o CouchSurfing e o AirBnb. Turismo em Análise, v. 29, n. 3, p. 447-467, 2018. Disponível em: $\quad$ http://www.spell.org.br/documentos/ver/55217/comportamento-do-consumidor-na-economiacompartilhada-no-turismo $\%$ E2\%80\%93um-estudo-sobre-o-couchsurfing-e-o-airbnb. Acesso em: 16 jun. 2020. 